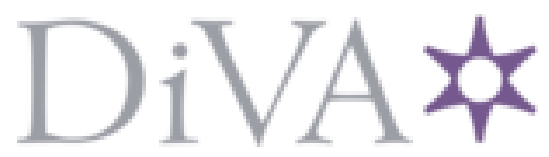

http://www.diva-portal.org

This is the published version of a paper published in Journal of Nuclear Materials.

Citation for the original published paper (version of record):

Rubel, M., De Temmerman, G., Sergienko, G., Sundelin, P., Emmoth, B. et al. (2007)

Fuel removal from plasma-facing components by oxidation-assisted technique: An overview of surface morphology after oxidation.

Journal of Nuclear Materials, 363-365: 877-881

http://dx.doi.org/10.1016/j.jnucmat.2007.01.107

Access to the published version may require subscription.

N.B. When citing this work, cite the original published paper.

Permanent link to this version:

http://urn.kb.se/resolve?urn=urn:nbn:se:kth:diva-68815 


\title{
Fuel removal from plasma-facing components by oxidation-based techniques. An overview of surface conditions after oxidation
}

\author{
M.J. Rubel ${ }^{\mathrm{a}, *}$, G. De Temmerman ${ }^{\mathrm{b}}$, G. Sergienko ${ }^{\mathrm{c}}$, P. Sundelin ${ }^{\mathrm{a}}$, \\ B. Emmoth ${ }^{\text {d }}$, V. Philipps ${ }^{\mathrm{c}}$ \\ a Alfvén Laboratory, School of Electrical Engineering, Royal Institute of Technology (KTH), Association EURATOM-VR, \\ 10044 Stockholm, Sweden \\ ${ }^{\mathrm{b}}$ Institute of Physics, University of Basel, CH-4056 Basel, Association EURATOM-Confédération Suisse, Switzerland \\ ${ }^{c}$ Institute of Plasma Physics, Forschungszentrum Jülich, Association EURATOM-FZJ, D-52425 Jülich, Germany \\ ${ }^{\mathrm{d}}$ Department of Microelectronics, Royal Institute of Technology (KTH), Association EURATOM-VR, 16440 Kista, Sweden
}

\begin{abstract}
Oxygen-assisted fuel removal is reported for laboratory-prepared a-C:D films and for layers obtained by boronisation in a tokamak and then exposed to a helium-oxygen glow discharge in TEXTOR. Oxidation of thick mixed-material co-deposits under laboratory conditions is also presented. The essential results are following: (i) laboratory-prepared amorphous deuterated carbon (a-C:D) layers are decomposed efficiently by the $\mathrm{He}-\mathrm{O}_{2}$ glow: $\mathrm{D}$ and $\mathrm{C}$ contents are decreased by a factor of 45-220 and 25-60, respectively; (ii) the same treatment of the boronised films leads to the release of D but no removal of carbon is observed; (iii) the thermal oxidation (at $300{ }^{\circ} \mathrm{C}$ in air under laboratory conditions) of co-deposits on PFC and probes exposed to the SOL reduces the D content by a factor of 4-5 after $2 \mathrm{~h}$, whereas nearly complete fuel removal $(98 \%)$ occurs after $10 \mathrm{~h}$ at $300{ }^{\circ} \mathrm{C}$. The study shows that the fuel removal efficiency is dependent on the overall composition of the mixed layer. It is high from pure a-C:D films but distinctly less efficient from real co-deposits.
\end{abstract}

(C) 2007 Elsevier B.V. All rights reserved.

PACS: $52.40 . \mathrm{Hf}$

Keywords: Deuterium inventory; Retention; Surface analysis; Co-deposition; TEXTOR

\footnotetext{
* Corresponding author. Address: Alfvén Laboratory, School of Electrical Engineering, Royal Institute of Technology (KTH), Teknikringen 31, 10044 Stockholm, Sweden. Fax: +468790 6574.

E-mail address: rubel@kth.se (M.J. Rubel).
}

\section{Introduction}

Reduction of long-term fuel inventory in plasmafacing components (PFC) is one of the most urgent and challenging tasks to be resolved to ensure the safe and economic operation of a reactor-class fusion device. Among several proposed methods [1-6], the approach based on the oxidation-assisted 
fuel removal is considered to be an important option [7-17]. There are three outstanding issues associated with every technique aiming at the reduction of fuel content and removal of co-deposits: (i) the efficiency of fuel removal and the recession rate of the co-deposited layer, (ii) surface condition of PFC following the treatment and (iii) dust formation accompanying the disintegration of co-deposits. The aim of this paper is to provide an overview of surface studies performed for deuterium-containing layers following their exposure to a $\mathrm{He}-\mathrm{O}_{2}$ glow discharge in the TEXTOR tokamak or thermal oxidation under laboratory conditions.

\section{Experimental}

The study was carried out with laboratory-prepared pure amorphous deuterated carbon films (a-C:D) and pre-boronised layers (boronisation in TEXTOR with hydrogenated diborane: $\mathrm{B}_{2} \mathrm{H}_{6}$ ). Both types of films deposited on silicon substrates were mounted on a holder and inserted into the tokamak for the $\mathrm{He}-\mathrm{O}_{2}$ glow. Detailed descriptions of conditions for the in-situ oxidation experiment can be found elsewhere [17]. Studies were also performed for mixed-material co-deposits formed on TEXTOR limiters during the long-term plasma operation (over $4 \mathrm{~h}$ of plasma) and on short-term probes exposed for $74 \mathrm{~s}$ to the scrape-off layer (SOL) plasma. They were oxidised at elevated temperature $\left(300\right.$ and $550{ }^{\circ} \mathrm{C}$ in air) under laboratory conditions using a tube oven. Several samples of co-deposits were also annealed in vacuum at $1000{ }^{\circ} \mathrm{C}$ in order to determine the properties of codeposits after high-temperature treatment. To assess the fuel content, surface composition and surface structure before and after the oxidation, the study was performed by means of accelerator-based ion beam analysis (IBA) methods (nuclear reaction analysis - NRA, Rutherford back-scattering spectroscopy - RBS, enhanced proton scattering EPS), high resolution scanning electron microscopy (SEM), energy dispersive X-ray spectroscopy (EDS) and sputter-assisted X-ray photoelectron spectroscopy (XPS) applying a sputter erosion rate of $0.5 \mathrm{~nm} / \mathrm{s}$.

\section{Results}

\subsection{Oxidation by helium-oxygen glow in TEXTOR}

Deuterium, carbon and boron contents determined with IBA methods for a-C:D and pre-boronised layers before and after the exposure to a $\mathrm{He}-\mathrm{O}_{2}$ glow are compiled in Table 1 . The results indicate some scatter in the surface concentration of the analysed species but the general tendency may be summarised by the following. The deuterium content is reduced from $4-6 \times 10^{17} \mathrm{~cm}^{-2}$ to $3-9 \times 10^{15} \mathrm{~cm}^{-2}$ (approximately 45-220 times) and the amount of carbon is decreased approximately from $8-10 \times$ $10^{17} \mathrm{~cm}^{-2}$ to $14-37 \times 10^{15} \mathrm{~cm}^{-2}$ (25-60 times with exception of sample 1:500 times) in the a-C:D samples. In the films obtained by boronisation in TEXTOR with $\mathrm{B}_{2} \mathrm{H}_{6}$, the $\mathrm{D}$ content is also reduced low level $\left(0.7-3.0 \times 10^{15} \mathrm{~cm}^{-2}\right)$ but the initial deuterium amount was small $\left(17 \times 10^{15} \mathrm{~cm}^{-2}\right)$ because of hydrogenated diborane used for the layer preparation. This makes the direct comparison of deuterium removal efficiency from both types of layers rather difficult. The boron content is lowered by $20 \%$ by the glow discharge and this reduction may be attributed to physical sputtering by helium and oxygen species. The amount of carbon in the boronised sample is generally small but one can notice that it has been even somewhat increased in comparison to the initial value. There are two plausible explanations of this fact: (i) some carbon removed

Table 1

Initial and post-oxidation concentrations of deuterium, carbon and boron in samples treated at TEXTOR

\begin{tabular}{|c|c|c|c|c|c|c|}
\hline $\begin{array}{l}\text { Type of sample } \\
\text { (sample number) }\end{array}$ & $\begin{array}{l}\text { D initial } \\
\left(10^{15} \mathrm{~cm}^{-2}\right)\end{array}$ & $\begin{array}{l}\text { D oxidised } \\
\left(10^{15} \mathrm{~cm}^{-2}\right)\end{array}$ & $\begin{array}{l}\mathrm{C} \text { initial } \\
\left(10^{15} \mathrm{~cm}^{-2}\right)\end{array}$ & $\begin{array}{l}\text { C oxidised } \\
\left(10^{15} \mathrm{~cm}^{-2}\right)\end{array}$ & $\begin{array}{l}\text { B initial } \\
\left(10^{15} \mathrm{~cm}^{-2}\right)\end{array}$ & $\begin{array}{l}\text { B oxidised } \\
\left(10^{15} \mathrm{~cm}^{-2}\right)\end{array}$ \\
\hline \multicolumn{7}{|l|}{$a-C: D$ layers } \\
\hline (1) & 486 & $3.4-7.4$ & 980 & 2 & 4 & $4-8$ \\
\hline (2) & 520 & $2.9-4.4$ & 875 & 27 & 8 & $8-12$ \\
\hline (3) & 638 & $2.9-8.7$ & 870 & 37 & - & - \\
\hline (4) & 411 & $2.9-9.2$ & 790 & 14 & - & - \\
\hline $\begin{array}{c}\text { Pre-boronised in } \\
\text { TEXTOR (5) }\end{array}$ & 17 & $0.7-3.0$ & 12 & $12-45$ & $290-318$ & $221-255$ \\
\hline
\end{tabular}


from the wall by oxidation was then non-uniformly re-deposited on that surface; and (ii) carbon was non-uniformly embedded in the layer during the boronisation at TEXTOR and it was not later removed by the oxidation because the boron layer blocked the oxygen access to carbon species. SEM images in Fig. 1 shows fine features of the a-C:D coating and the surface after oxidation. The corresponding X-ray photoelectron spectra are shown in Fig. 2. For the initial surface (Fig. 2(a)), the $\mathrm{C} 1 \mathrm{~s}$ photoelectron line at 285.5 indicates the presence of adsorbed carbon species. When this outermost layer $(2.5 \mathrm{~nm})$ is removed by sputtering, a clear peak typical for amorphous carbon is recorded at $284.4 \mathrm{eV}$. After the oxidation (Fig. 2(b)), only Si $2 p$ photoelectron lines related to the silicon substrate are recorded: oxidised silicon at $103.5 \mathrm{eV}$. After removing of the outermost $2.5 \mathrm{~nm}(5 \mathrm{~min}$ sputtering) the line shifts to $99.2 \mathrm{eV}$ which corresponds to the binding energy of pure silicon. In summary, the micrographs and spectra reveal that the layer was efficiently removed and a flat $\mathrm{Si}$ substrate is visible after oxidation. This supports the results of IBA studies (Table 1) which detected only minute amounts of $\mathrm{C}$ and $\mathrm{D}$ on the oxidised surface. No change in the surface structure has been observed in the pre-boronised layer when comparing the initial and oxidised coating.

\subsection{Oxidation and annealing under laboratory conditions}

The study was carried out with IBA and EDS methods for thick (over $180 \mu \mathrm{m}$ ) co-deposits formed on a graphite limiter protecting the RF antenna. The layer - besides carbon and deuterium - also contained a few percent of boron and other elements such as silicon and metals $(\mathrm{Ni}, \mathrm{Cr}, \mathrm{Fe}, \mathrm{Mo}$ from the Inconel liner). The results for deuterium content and deuterium-to-carbon concentration
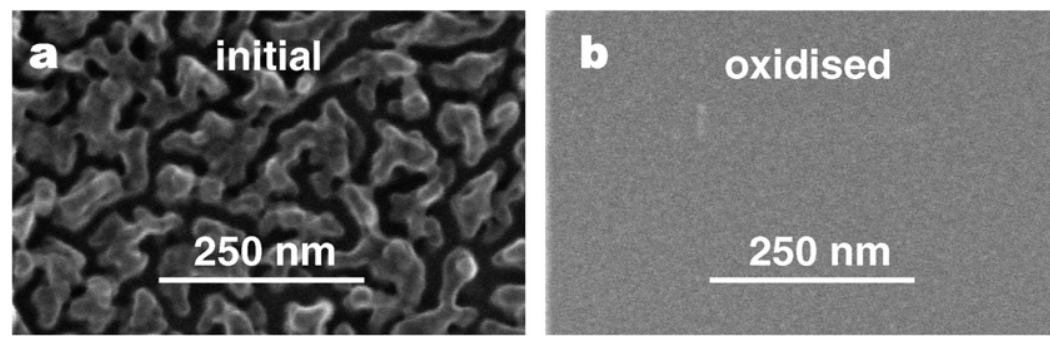

Fig. 1. Surface structure of: (a) original a-C:D coating and (b) the Si substrate after removal of the carbonised layer by oxidation.
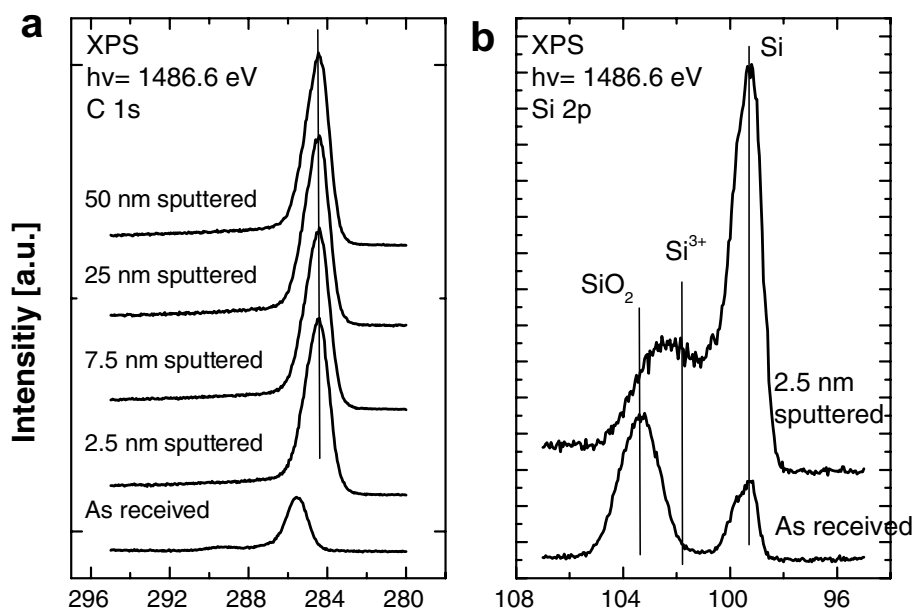

Binding energy (eV)

Fig. 2. X-ray photoelectron spectra recorded for: (a) the original a-C:D coating and (b) the Si substrate after removal of the carbonised layer by oxidation. 
Table 2

Deuterium content measured with NRA in the near surface region $(4.5 \mu \mathrm{m})$ of the flaking layer on the RF antenna protection limiter in the initial state and after oxidation in air or annealing in vacuum

\begin{tabular}{llll}
\hline Treatment & $\begin{array}{l}\mathrm{D} \text { content } \\
\left(10^{16} \mathrm{~cm}^{-2}\right)\end{array}$ & $\begin{array}{l}\text { Removal } \\
\text { efficiency }(\%)\end{array}$ & $\begin{array}{l}\mathrm{C}_{\mathrm{D}} / \mathrm{C}_{\mathrm{C}} \\
(\%)\end{array}$ \\
\hline $\begin{array}{c}\text { Original } \\
\text { surface }\end{array}$ & 121 & & 3.3 \\
$\begin{array}{c}300^{\circ} \mathrm{C} \text {, air, } \\
2 \mathrm{~h}\end{array}$ & 35 & 70 & 1.0 \\
$\begin{array}{c}300^{\circ} \mathrm{C} \text {, air, } \\
10 \mathrm{~h}\end{array}$ & 2.4 & 98 & 0.07 \\
$\begin{array}{c}550^{\circ} \mathrm{C} \text {, air, } \\
1 \mathrm{~h} \text {. }\end{array}$ & 7 & 94 & 0.19 \\
$\begin{array}{c}1000^{\circ} \mathrm{C} \text {, vac., } \\
1 \mathrm{~h}\end{array}$ & 6 & 95 & 0.16 \\
\hline
\end{tabular}

ratios $\left(\mathrm{C}_{\mathrm{D}} / \mathrm{C}_{\mathrm{C}}\right)$ after oxidation at elevated temperatures $\left(300\right.$ and $\left.550{ }^{\circ} \mathrm{C}\right)$ in air and annealing in vacuum are shown in Table 2. These data are for the layer thickness of $4.5 \mu \mathrm{m}$ which is the accessible information depth of NRA with a ${ }^{3} \mathrm{He}^{+}$beam of energy of $1.5 \mathrm{MeV}$. The exposure to air for $2 \mathrm{~h}$ at $300{ }^{\circ} \mathrm{C}$ results in the removal of about $75 \%$ of the fuel and the prolonged oxidation $(10 \mathrm{~h})$ at this temperature removes $98 \%$ of deuterium bringing the $\mathrm{C}_{\mathrm{D}} / \mathrm{C}_{\mathrm{C}}$ down to less then $1 \%$ (initial value: $3.3 \%$ ). At $550{ }^{\circ} \mathrm{C}$ in air the removal rate approaches $95 \%$. Similar result is obtained after $1 \mathrm{~h}$ annealing in vacuum at $1000{ }^{\circ} \mathrm{C}$ (the result is in good agreement with previously published data [18]), but for technical reasons the temperatures exceeding $300{ }^{\circ} \mathrm{C}$ are too high to be applied at ITER.

SEM images in Fig. 3(a)-(c) show surface topography of the initial and oxygen and vacuum treated samples, respectively. The results demonstrate that the surface topography and composition (carbon and co-deposited impurity atoms analysed with EDS) of the layer of 'tokamakium' on PFC change rather little even if the fuel is removed. The oxidation causes cracking of the layer whereas the annealing in vacuum leads also to the formation of holes in the co-deposit. It may be tentatively interpreted as the formation channels for deuterium release from deeper layers. From these studies carried out on graphite substrates it is not possible to assess, how much carbon is removed together with fuel. The comparison of thermal treatments (oxidation and annealing) shows that the most efficient fuel removal has occurred after the $10 \mathrm{~h}$ of oxidation in air at $300{ }^{\circ} \mathrm{C}$. Such baking conditions may likely be available intermittently in ITER. This might lead

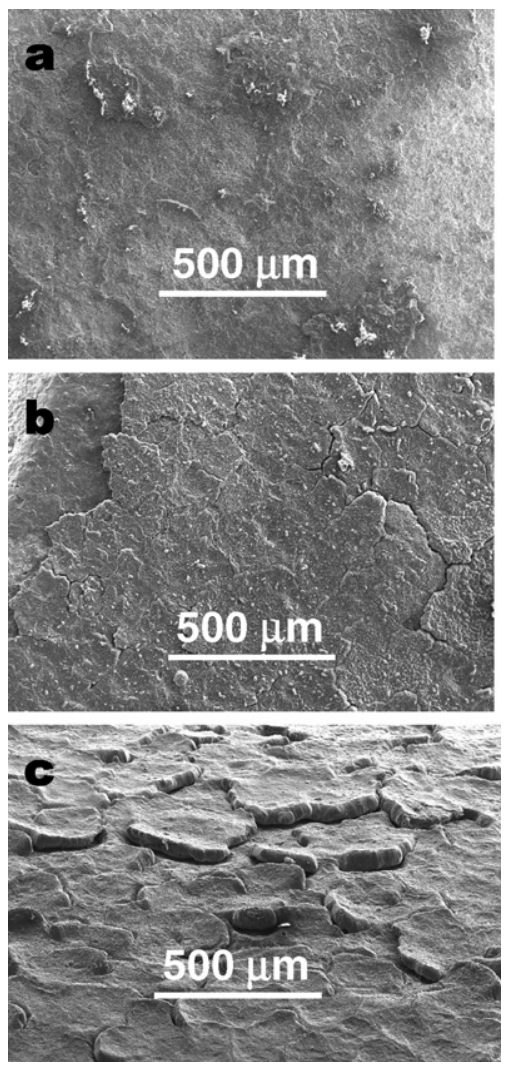

Fig. 3. Surface topography of the thick co-deposit on the RF antenna protection tile: (a) initial structure, (b) after $2 \mathrm{~h}$ oxidation in air at $300^{\circ} \mathrm{C}$ and (c) after annealing in vacuum for $1 \mathrm{~h}$ at $1000{ }^{\circ} \mathrm{C}$

to the reduction of fuel content in co-deposits on hot PFC, but probably not on surfaces in remote areas where the formation of thick layers is observed [19]. However, the study also indicates that the release of deuterium is not accompanied by the removal of co-deposits. It remains to be studied how the fuel-depleted porous co-deposits would behave upon the next exposure to the hydrogen plasma, i.e. whether the intense uptake of fuel species would occur on a short time scale.

\section{Oxidation of a short-term probe}

To check the influence of oxygen on thin codeposited films (up to $300 \mathrm{~nm}$ ) a short-term exposure (74 s of plasma operation) was performed in the freshly siliconised TEXTOR. Graphite plates ( $80 \mathrm{~mm}$ long) were mounted on the head of the collector probe [20] and positioned in the SOL. Plots in Fig. 4 shows the measurements (radial profiles) performed soon after the exposure and after 


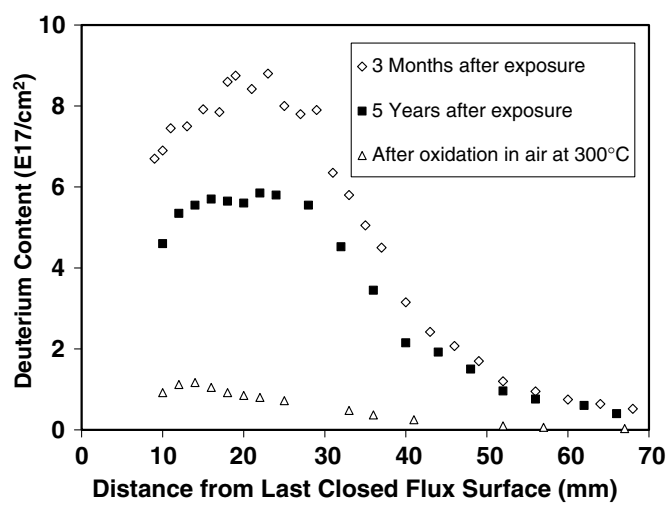

Fig. 4. D content in thin co-deposits before and after oxidation in air for $1 \mathrm{~h}$.

three years of storage in air. This second measurement was followed by the plate oxidation in air for $1 \mathrm{~h}$ at $300^{\circ} \mathrm{C}$. The long storage has resulted in the release of $25-30 \%$ of deuterium. The oxidation in air has removed most of the deuterium but the process was been complete after $1 \mathrm{~h}$. One may tentatively suggest that the presence of $\mathrm{Si}$ in the layer inhibits the access of oxygen and - eventually slows the process of fuel removal. The amount of $\mathrm{Si}$ was also measured at each stage: initial, after storage and after oxidation, e.g. $2 \times 10^{17} \mathrm{~cm}^{-2}$ at the distance of $30 \mathrm{~mm}$ from the last closed flux surface. No difference has been found.

\section{Concluding remarks}

The study has shown that the oxidation - as expected - reduces the amount of deuterium retained in the layers. For laboratory-prepared thin pure a-C:D layers on $\mathrm{Si}$ the release of deuterium is accompanied by the efficient removal of carbon. The most efficient deuterium release has been observed from thermally oxidised real co-deposits baked in air for $10 \mathrm{~h}$ in air at $300^{\circ} \mathrm{C}$. However, these real co-deposits - either thin or thick - are not fully decomposed, showing that the recession rate of a mixed co-deposit is much slower than that of a pure amorphous deuterated film. It allows for the tentative conclusion that the removal efficiency of carbon-containing deposits may be dependent on the overall composition of mixed layer composed also of elements (e.g. B, Si, and metals) not transferred to volatile compounds. Two reasons may be considered: (i) the presence of admixtures slows the process by inhibiting the penetration of oxygen into the depth of co-deposits and the diffusion of volatile reaction products to the surface; and (ii) carbon is partly bonded to $\mathrm{Si}$ or B in the form of carbides. The presence of other carbides, silicides and borides or oxides (in all cases with metal impurities) cannot be excluded, but with techniques used in this study, one cannot directly prove the presence of carbides and other compounds on the surfaces of probes or limiters. Similar effects influencing the fuel release rate and efficiency may probably be foreseen in case of Be-containing films.

\section{Acknowledgements}

The work was partly carried out under the Contract 621-2003-3170 from the Swedish Research Council and EURATOM Mobility for Staff Movements. This work, supported by the European Communities under the Contract of Association between EURATOM/VR, was carried out within the framework of the European Fusion Development Agreement. The views and opinions expressed herein do not necessarily reflect those of the European Commission.

\section{References}

[1] P. Andrew et al., Fus. Eng. Des. 47 (1999) 233.

[2] C.H. Skinner et al., J. Nucl. Mater. 313-316 (2003) 496.

[3] G. Counsell, C.H. Wu, Phys. Scr. T 91 (2001) 70.

[4] W. Shu et al., Appl. Phys. A 76 (2003) 421.

[5] P. Gasior et al., Phys. Scr. T 123 (2006) 99.

[6] J.P. Coad et al., J. Nucl. Mater., these Proceedings, doi:10.1016/j.jnucmat.2007.01.074.

[7] J.W. Davis, A.A. Haasz, Phys. Scr. T 91 (2001) 33.

[8] R.A. Causey, W.R. Wampler, D. Walsh, J. Nucl. Mater. 176\&177 (1990) 992.

[9] W. Wang, W. Jacob, J. Roth, J. Nucl. Mater. 245 (1997) 66.

[10] V. Philipps et al., J. Nucl. Mater. 266-269 (1999) 386.

[11] B. Landkammer, A. von Keudell, W. Jacob, J. Nucl. Mater. 264 (1999) 48.

[12] K. Maruyama, W. Jacob, J. Roth, J. Nucl. Mater. 264 (1999) 56.

[13] M. Rubel et al., J. Nucl. Mater. 266-269 (1999) 1185.

[14] M. Rubel, A. Vevecka-Priftaj, V. Philipps, Mater. Sci. Eng. A 272 (1999) 174.

[15] V. Philipps et al., in: Proceedings of the 32nd EPS Plasma Physics Conference, Europhysics Conference Abstracts 29 (2005) P1-024.

[16] C. Hopf et al., J. Nucl. Mater., these Proceedings, doi:10.1016/j.jnucmat.2007.01.108.

[17] V. Philipps et al., J. Nucl. Mater., these Proceedings, doi:10.1016/j.jnucmat.2007.01.107.

[18] M. Rubel et al., J. Nucl. Mater. 196-198 (1992) 285.

[19] M. Rubel et al., J. Nucl. Mater. 313-316 (2003) 321.

[20] M. Rubel et al., J. Nucl. Mater. 220-222 (1995) 536. 